\section{Profissionais e trabalhadores de saúde no Brasil: para onde vamos?}

Health professionals and workers in Brazil: where do we go from here?

\section{Carmen Fontes de Souza Teixeira ${ }^{1}$}

O artigo "Trabalho e Educação em saúde no Brasil" inscreve-se em uma linhagem de estudos que visam, periodicamente, mapear as tendências da produção científica em determinada área, com o intuito de identificar os problemas, os objetos e as abordagens teórico-metodológicas que vêm sendo desenvolvidas. Neste caso, trata-se de caracterizar a produção recente (1990 a 2010) sobre a formação de pessoal e a organização e gestão do trabalho em saúde, tema complexo que, como assinalam as autoras, faz parte da "agenda de pesquisa” da saúde coletiva desde seus primórdios.

Destaco o fato de o artigo resgatar os trabalhos pioneiros que operaram uma ruptura com os estudos sobre "recursos humanos em saúde", de viés economicista, inaugurando a análise crítica das questões relativas ao trabalho e à educação em saúde na perspectiva da economia política marxista, ponto de partida para a diversificação de abordagens que, contemporaneamente, valorizam as múltiplas dimensões analíticas do processo de trabalho em saúde e dos seus agentes, os profissionais e trabalhadores de saúde. Além disso, considero importante que as autoras tenham se ancorado na revisão de estudos anteriores que mapearam a produção científica na área, o que possibilita aos pesquisadores que se iniciam neste campo, recuperar as características da produção científica nos últimos 35 anos.

Especificamente com relação ao estudo realizado, cabe destacar a pertinência do recorte temporal, correspondente ao período de implantação do SUS, concomitante à expansão e diversificação do SAMS. As autoras assumem o pressuposto de que tais processos incidiram sobre a configuração do mercado de trabalho em saúde, na organização das práticas dos profissionais e trabalhadores, nos processos de formação e capacitação de pessoal e na ação desenvolvida pelo Estado através das políticas e práticas de gestão do trabalho implementadas nas instituições (públicas e privadas) de ensino e de prestação de serviços de saúde. Tal pressuposto se evidencia não só na seleção dos descritores que orientaram a busca e seleção dos resumos de trabalhos que foram capturados nas bases bibliográficas pesquisadas, senão que aparece à proporção que os resultados vão sendo apresentados, sob a forma de hipóteses explicativas das características da produção em cada uma das categorias nas quais os resumos foram colocados.

Alguns aspectos chamam a atenção e permitem que se identifiquem, através do mapeamento e análise da produção científica selecionada, os processos que vêm ocorrendo no âmbito das instituições de ensino e serviço, os problemas que vêm sendo discutidos e analisados, bem como algumas propostas implantadas e avaliadas no âmbito da formação de pessoal e das políticas de educação permanente e gestão do trabalho nas instituições de saúde.

Em primeiro lugar, é interessante constatar que a grande maioria dos trabalhos analisados $(71 \%$ do total de 532 resumos) trata da "Formação/capacitação dos trabalhadores de saúde”, dos quais a maior parte relata experiências desenvolvidas em cursos de educação superior, ou seja, nos cursos profissionalizantes da área de saúde, destacando-se os relatos acerca de reformas curriculares e experiências de articulação ensino-serviço. Ora, isto provavelmente expressa o interesse dos próprios docentes envolvidos em registrar e analisar suas experiências, o que, apesar de louvável, revela o quanto do debate sobre a formação de pessoal em saúde ainda não superou a reprodução do modelo de formação construído no século passado, estruturado segundo as profissões derivadas da divisão técnica e social do paradigma biomédico, hegemônico no sistema de serviços de saúde e na universidade brasileira.

Considerando que a crítica a este modelo de formação muitas vezes se encerra nos limites dos próprios cursos profissionais, gostaria de provocar as autoras a comentar o que de inovador, seja do ponto de vista da criação de novos cursos, a exemplo da graduação em saúde coletiva, seja na reorientação dos processos ensino-aprendizagem nos cursos existentes, elas encontraram na leitura dos resumos dos trabalhos incluídos nesta categoria. Ou seja, até que ponto os pesquisadores da área estão discutindo as profundas mudanças científicas, tecnológicas, organizacionais e políticas que vêm ocorrendo na sociedade contemporânea e suas repercussões na organização do processo de trabalho na área de saúde? Além disso, até que ponto a produção científica sobre a formação de pessoal em saúde está incorporando o debate sobre a reestruturação do ensino profissional, principalmente no nível superior?

Coloco esta questão porque gostaria que as autoras discorressem sobre o que encontraram na pro-

\footnotetext{
Instituto de Humanidades, Artes e Ciências Prof. Milton Santos, Universidade Federal da Bahia.carment@ufba.br
} 
dução científica que pode subsidiar o debate acerca da introdução de mudanças na arquitetura acadêmica das universidades, no desenho dos cursos e nos conteúdos e práticas pedagógicas, tendo em vista a formação de profissionais dotados de capacidade crítica, sensibilidade social, flexibilidade de inserção nas equipes de saúde e capazes de atuar dignamente numa sociedade multicultural, multiétnica e ainda profundamente desigual como a brasileira.

Em segundo lugar, gostaria de comentar outro achado importante do trabalho, qual seja, as tendências verificadas na produção científica incluídas nas categorias "Mercado de trabalho, Política e Administração de recursos humanos em saúde". Apesar do menor volume de trabalhos (apenas 12,7\% do total) os estudos revelam os processos que vem ocorrendo no mercado de trabalho no setor, dando continuidade a tendência já identificada há várias décadas como o assalariamento, sobre a qual se justapõe a tendência à "precarização" das relações de trabalho. Os estudos confirmam, portanto, a existência de um fenômeno cada vez mais visível no cotidiano dos sistemas (publico e privado) na área de saúde, fruto da desregulamentação do mercado, em função, inclusive, da implementação de políticas de corte neoliberal que tendem a escamotear os direitos trabalhistas, gerando insegurança, insatisfação e profundo mal-estar nos profissionais e trabalhadores da área.

Finalmente, gostaria de chamar a atenção para as características da produção incluída na categoria "Profissionais/agentes do trabalho em saúde" responsável por $14 \%$ do total de resumos analisados. Não fica claro de que tratam os estudos sobre "processo de trabalho em saúde". Os demais abordam principalmente questões como "competência, perfil, identidade profissional”, além de um pequeno número que discute a "saúde do trabalhador da saúde”. Refletindo sobre o conjunto da produção, entretanto, parece-me que existe uma lacuna extremamente importante, ou seja, a escassez (ou inexistência?) de estudos sobre a concepção e o posicionamento político dos profissionais e trabalhadores de saúde, seja em relação à sua prática seja em relação ao sistema e à política de saúde. Recordo do trabalho seminal de Cecília Donangello1, "Medicina e sociedade" (1975), o capítulo que discute as "ideologias ocupacionais", explicitando a visão dos médicos sobre sua prática e seu posicionamento diante das tendências do mercado de trabalho, analisadas pela Autora nos capítulos anteriores. Também me vem à lembrança o estudo de Gastão Wagner ${ }^{2}$ sobre "Os médicos e a política de saúde" (1989), no qual analisava o movimento de Renovação Médica, um dos sujeitos políticos coletivos do processo de Reforma Sanitária Brasi- leira, nos anos 70/80. Com isso quero problematizar a ausência de estudos que caracterizem o "perfil” e a movimentação política dos profissionais e trabalhadores de saúde na atual conjuntura. Afinal, investigações dessa natureza são necessárias para subsidiar análises políticas mais fundamentadas do que vem se passando no Brasil nos últimos 20 anos. Estudos que vem sendo feitos na área de Política, Planejamento e Gestão, sugerem que os efeitos do processo de construção do SUS e de expansão do SAMS, ultrapassam as mudanças nas condições de trabalho e remuneração dos profissionais de saúde e se expressam na redefinição de posições políticas desses profissionais, as quais podem ser identificadas e analisadas através de pesquisas que tomem como objeto a atuação das entidades representativas das diversas categorias de trabalhadores, nos espaços de formulação de políticas e na negociação com os gestores públicos e privados.

Creio, portanto, ser necessário destacar essa lacuna nos estudos, porquanto não ser suficiente que se discuta os desafios enfrentados pelos gestores que se ocupam de políticas de "educação permanente" ou da introdução de dispositivos reguladores para adequar o perfil dos profissionais egressos das escolas e universidades às práticas $\mathrm{e}$ processos de trabalho nos serviços. A produção de conhecimentos sobre as propostas e as ações políticas dos profissionais e trabalhadores de saúde pode contribuir para o aprofundamento do debate acerca das bases de sustentação do projeto da Reforma Sanitária e de construção do SUS. São necessários e urgentes estudos que mapeiem e caracterizem os atores políticos que estão (ou não) se configurando no universo de profissionais e trabalhadores (mais de dois milhões de pessoas) que atuam nas diversas modalidades de organização das ações e serviços, e se vinculam, direta ou indiretamente, às entidades que buscam representálos diante das instâncias políticas de tomada de decisão na área de saúde, como sindicatos, associações, conselhos profissionais, grupos de pressão vinculados a empresas médicas e parlamentares cujas bases eleitorais incluem profissionais e trabalhadores de saúde.

\section{Referências}

1. Donnangelo MCF. Medicina e Sociedade: o médico e seu mercado de trabalho. São Paulo: Pioneira; 1975.

2. Campos GWS. Os médicos e a política de saúde: entre a estatização e o empresariamento dos serviços de saúde [dissertação]. São Paulo: Universidade de São Paulo; 1986. 